\section{Factors associated with vaginal detection of prostate-specific antigen among participants in a clinical trial in Malawi}

Self-report of sexual behaviours in clinical studies is often subject to misreporting due to recall or social desirability bias or misinterpretation of the study questionnaires. $^{1}$ Use of biomarkers of semen exposure, such as the detection of prostate-specific antigen (PSA) in vaginal secretions, offers an additional means of assessing sexual behaviours and condom use that is not subject to reporting biases. $^{2}$ In a secondary analysis of a clinical trial of hormonal contraception in Malawi, ${ }^{3}$ we examined associations of discordance between PSA detection and self-report of condomless sex over time with participant characteristics using log-binomial regression analyses with generalised estimating equations for repeated measures. All analyses were conducted using SAS V.9.3 (SAS Institute, Cary, North Carolina, USA). Testing for PSA was performed using the ABAcard p30 rapid immunochromatographic strip test (Abacus Diagnostics, West Hills, California, USA); samples containing $\geq 1.0$ ng PSA $/ \mathrm{mL}$ were considered positive for detection of semen, as previously described. ${ }^{4}$ Discordance between PSA detection and self-report was defined as detection of PSA in the vaginal samples, with report of condom use at last sex or no sex since last study visit. Given the rapid clearance of PSA, negative results for PSA were not considered in the definition of discordance or concordance, regardless of whether condomless sex was self-reported or not. ${ }^{4}$

This analysis included 539 vaginal swabs from 97 women. Most women were HIVpositive (75.3\%), married (70.1\%); 40.2\% had not completed primary education; their mean age was 32.5 years and median number of children was three. Fifty-four $(55.7 \%)$ women reported unprotected sex at least once during the study. At least once during follow-up, $56.7 \%$ of women tested positive for PSA. PSA detection was significantly associated with younger age, HIV-negative status, and self-report of sex within 48 hours of a study visit (table 1 ). Of PSA-positive samples, 62.3\% (66/106) were discordant with self-report. HIVpositive status (prevalence ratio (PR): 1.74, 95\% CI: 1.19 to 2.54 ) and noncompletion of primary school education

Table 1 Factors associated with vaginal PSA detection and with discordance (between PSA test result and self-report of sexual activity), progestin study, Lilongwe, Malawi

\begin{tabular}{|c|c|c|c|c|}
\hline & \multicolumn{2}{|l|}{ PSA detected } & \multicolumn{2}{|l|}{ Discordance } \\
\hline & Adjusted PR* & $95 \% \mathrm{Cl}$ & Adjusted PR* & $95 \% \mathrm{Cl}$ \\
\hline Self-reported condomless last sex in last 48 hours & 2.46 & 1.7 to 3.57 & 0.77 & 0.57 to 1.05 \\
\hline Last coitus within 48 hours & $4.45+$ & 2.88 to 6.88 & 0.55 & 0.14 to 2.10 \\
\hline HIV-positive (vs HIV-negative) & 0.59 & 0.09 to 0.38 & 1.74 & 1.19 to 2.54 \\
\hline Younger age (per decrease 1 year) & 1.04 & 1.00 to 1.08 & $\ddagger$ & \\
\hline Parity (per increase of 1 ) & 0.87 & 0.75 to 1.01 & 0.98 & 0.91 to 1.07 \\
\hline Married (vs not married) & 1.26 & 0.71 to 2.21 & 0.94 & 0.72 to 1.24 \\
\hline $\begin{array}{l}\text { Did not complete primary school education (vs completed or } \\
\text { more than primary) }\end{array}$ & 0.93 & 0.57 to 1.49 & 1.42 & 1.12 to 1.78 \\
\hline
\end{tabular}

Bold values are statiscally significant.

*All models adjusted for study arm and pre-randomisation vs post-randomisation visits.

tAdditionally adjusted for age.

$¥$ Non-estimable due to small sample size.

95\% Cl, 95\% Confidence Interval; PR, prevalence ratio; PSA, prostate-specific antigen.

(PR: 1.42, 95\% CI: 1.12 to 1.78$)$ were associated with such discordance (table 1).

In our study, PSA detection was less prevalent among HIV-positive women than HIV-negative women. However, discordance between PSA test result and self-report of sexual activity was more prevalent among HIV-positive women and women who did not complete primary school education. We were unable to evaluate qualitative or individual reasons for such discordance. Misclassification of sexual exposure and misreported condom use can overestimate or underestimate associations of sexual behaviours with clinical outcomes, such as transmission of HIV, other STIs ${ }^{5}$ or pregnancy. Incorporating objective biomarkers of sexual exposure in research studies may mitigate the biases of self-report. Marica M Hobbs, ${ }^{3}$ Dana Lapple, ${ }^{3}$ Lameck Chinula, ${ }^{4,5}$ Gerald Tegha, ${ }^{5}$ Albans Msika, ${ }^{5}$ Jennifer Tang, ${ }^{4,5}$ Athena P Kourtis ${ }^{1}$

${ }^{1}$ Division of Reproductive Health, Centers for Disease Control and Prevention, Atlanta, Georgia, USA

${ }^{2}$ Association of Schools and Programs of Public Health, Washington, DC, USA

${ }^{3}$ Division of Infectious Disease, University of North Carolina at Chapel Hill School of Medicine, Chapel Hill, North Carolina, USA

${ }^{4}$ School of Medicine, University of North Carolina at Chapel Hill, Chapel Hill, North Carolina, USA ${ }^{5}$ UNC Project, Lilongwe, Central Region, Malawi

Correspondence to Ms Yasaman Zia, Division of Reproductive Health, Centers for Disease Control and Prevention, Atlanta, GA 30341, USA; yaszia@gmail.com

Contributors APK, JT, LC were involved in the planning, conduct and design of the clinical trial. JT, LC, GT, AM collected data and specimens. MMH, DL produced the lab results. YZ, ND, JW performed the statistical analysis. JT, APK, YZ interpreted the data. All authors have contributed to the manuscript and have read and approved the paper.

Funding This work was supported by the Centers of Disease Control and Prevention and Association of Schools and Programs of Public Health (6NU360E000002)

Disclaimer The findings and conclusions in this report are those of the authors and do not necessarily represent the official position of the US Centers for Disease Control and Prevention, other funding agencies or the US Government. YZ is no longer a CDC affiliate.

Competing interests None declared.

Patient consent for publication Not required.

Provenance and peer review Not commissioned; internally peer reviewed.

(C) Author(s) (or their employer(s)) 2021. No commercial re-use. See rights and permissions. Published by BMJ.

\section{Check for updates}

To cite Zia Y, Davis N, Wiener J, et al. Sex Transm Infect 2021;97:77.

Received 28 April 2020

Accepted 2 May 2020

Published Online First 11 June 2020

Sex Transm Infect 2021;97:77.

doi:10.1136/sextrans-2020-054566

ORCID iD

Yasaman Zia http://orcid.org/0000-0001-6049-3706

\section{REFERENCES}

1 Phillips AE, Gomez GB, Boily M-C, et al. A systematic review and meta-analysis of quantitative interviewing tools to investigate self-reported HIV and STI associated behaviours in low- and middle-income countries. Int J Epidemiol 2010;39:1541-55.

2 Gallo MF, Behets FM, Steiner MJ, et al. ProstateSpecific antigen to ascertain reliability of selfreported Coital exposure to semen. Sex Transm Dis 2006;33:476-9

3 Kourtis AP, Haddad L, Tang J, et al. A randomized clinical trial on the effects of progestin contraception in the genital tract of HIV-infected and uninfected women in Lilongwe, Malawi: addressing evolving research priorities. Contemp Clin Trials 2017;52:27-34

4 Hobbs MM, Steiner MJ, Rich KD, et al. Good performance of rapid prostate-specific antigen test for detection of semen exposure in women: implications for qualitative research. Sex Transm Dis 2009:36:501-6.

5 Smith JA, Heffron R, Butler AR, et al. Could misreporting of condom use explain the observed association between injectable hormonal contraceptives and HIV acquisition risk? Contraception 2017:95:424-30. 